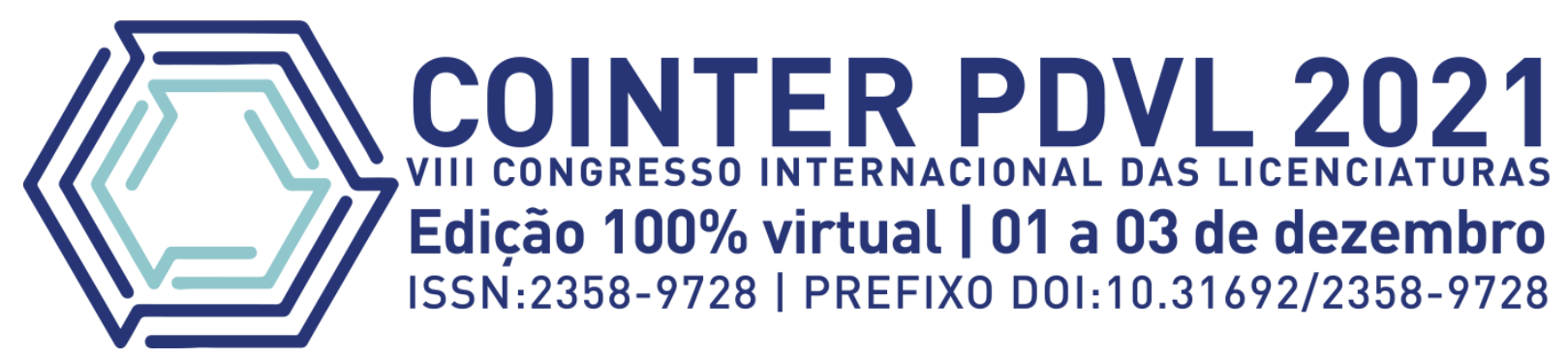

\title{
PROPOSTA DE USO DE LISTAS DE EXERCÍCIOS CONTEXTUALIZADAS PARA O ENSINO DE TERMOLOGIA
}

\section{PROPOSAL FOR THE USE OF CONTEXTUALIZED EXERCISES LISTS FOR THE TEACHING OF TERMOLOGY}

\section{PROPUESTA DE USO DE LISTAS DE EJERCICIOS CONTEXTUALIZADOS PARA LA ENSEÑANZA DE TERMOLOGÍA}

\author{
Apresentação: Comunicação Oral \\ Emanuel Victor Leal ${ }^{1}$; Rayssa Vanuza da Rocha ${ }^{2}$; Yam Ydo da Silva Fontalba Carrasco ${ }^{3}$; Italo Marcos de Lima ${ }^{4}$; \\ Haroldo Reis Alves de Macêdo 5
}

\begin{abstract}
RESUMO
O presente artigo tem como intuito apresentar o trabalho de ensino realizado com o auxílio e com o uso de listas de exercícios que contemplam de forma mais concisa o ensino de termodinâmica na disciplina de Física no ensino médio. Sabendo disso, é importante destacar que o trabalho tem como objetivo principal apresentar a solidificação recorrente do uso destas atividades em sala de aula, por aqueles que buscam proporcionar aos seus alunos um melhor entendimento do assunto, o que acaba por proporcionar a interação e um melhor aprendizado e de certa forma, diminuir a visão que muitos têm - de que a física é uma vilã -, e trazer para as escolas e alunado uma melhor forma de ensino-aprendizagem, como metodologias e práticas pedagógicas não tão saturadas como acontece nos dias atuais. O artigo trabalha principalmente sob as perspectivas e visão do ensino da física, notadamente a termodinâmica. Tudo isso foi embasado nos estudos de pessoas como Tipler (2009), Mosca (2009), Hewitt (2015), entre outros teóricos que complementam a pesquisa de forma significativa. Por outro lado, a metodologia se trata de uma pesquisa bibliográfica e descritiva, uma vez que apresenta atividades e além disso, se trata também uma pesquisa exploratória, que através de uma lista de exercícios que tem como objetivos específicos propiciar um melhor entendimento acerca do calor, do termômetro e da temperatura. Como conclusão, pode-se dizer que os exercícios serviram para que os alunos contextualizarem e aprendessem mais o conteúdo de forma mais dinâmica, consequentemente mais eficiente. Dessa forma levando esse conhecimento obtido para a sua vida cotidiana.
\end{abstract}

Palavras-Chave: Termodinâmica, Ensino da física, Aprendizagem Física.

\footnotetext{
${ }^{1}$ Licenciatura em Física, Instituto Federal do Piauí Campus Picos, emanuelvictorleal@ hotmail.com

${ }^{2}$ Licenciatura em Física, Instituto Federal do Piauí Campus Picos, rayssar975@gmail.com

${ }^{3}$ Licenciatura em Física, Instituto Federal do Piauí Campus Picos, yam.fontalba@gmail.com

${ }^{4}$ Licenciatura em Física, Instituto Federal do Piauí Campus Picos, profitalolima@ hotmail.com

${ }^{5}$ Doutor, Instituto Federal do Piauí Campus Picos, haroldoram@ifpi.edu.br
} 


\title{
PROPOSTA DE USO DE LISTAS DE EXERCÍCIOS
}

\section{RESUMEN}

Este artículo tiene como objetivo presentar el trabajo docente realizado con la ayuda y uso de listas de ejercicios que contemplan de manera más concisa la enseñanza de la termodinámica en la disciplina de la Física en el bachillerato. Sabiendo esto, es importante resaltar que el objetivo principal del trabajo es presentar la solidificación recurrente del uso de estas actividades en el aula, por parte de quienes buscan brindar a sus alumnos una mejor comprensión de la asignatura, lo que termina brindar interacción y un mejor aprendizaje y, de alguna manera, reducir la visión que muchos tienen --que la física es un villano--, y llevar a las escuelas y a los estudiantes una mejor forma de enseñar y aprender, con metodologías y prácticas pedagógicas no tan saturadas como son hoy. El artículo trabaja principalmente desde las perspectivas y visión de la enseñanza de la física, especialmente la termodinámica. Todo esto se basó en los estudios de personas como Tipler (2009), Mosca (2009), Hewitt (2015), entre otros teóricos que complementan significativamente la investigación. Por otro lado, la metodología es una investigación bibliográfica y descriptiva, ya que presenta actividades y, además, también es una investigación exploratoria, que a través de una lista de ejercicios que tienen como objetivos específicos proporcionar una mejor comprensión del calor, termómetro y temperatura. En conclusión, se puede decir que los ejercicios ayudaron a los estudiantes a contextualizar y aprender más sobre el contenido de una manera más dinámica y, en consecuencia, de manera más eficiente. De esta manera, llevar este conocimiento adquirido a su vida diaria.

Palabras Clave: Termodinámica, Enseñanza de la Física, Aprendizaje físico.

\begin{abstract}
This article aims to present the teaching work carried out with the help and use of exercise lists that more concisely contemplate the teaching of thermodynamics in the discipline of Physics in high school. Knowing this, it is important to highlight that the main objective of the work is to present a recurrent solidification of the use of these activities in the classroom, by those who seek to provide their students with a better understanding of the subject, which ends up providing interaction and a better learning and, in a way, reduce the view that many have - that physics is a villain -, and bring to schools and students a better way of teaching and learning, with methodologies and pedagogical practices not as saturated as they are today. The article works mainly from the perspectives and vision of the teaching of physics, especially thermodynamics. All of this was based on the studies of people such as Tipler (2009), Mosca (2009), Hewitt (2015), among other theorists who significantly complement the research. On the other hand, the methodology is a bibliographical and descriptive research, as it presents activities and, in addition, it is also an exploratory research, which through a list of exercises that have as specific objectives to provide a better understanding of heat, thermometer and temperature. In conclusion, it can be said that the exercises helped students to contextualize and learn more about the content in a more dynamic way, consequently more efficiently. In this way, taking this knowledge gained into your daily life.
\end{abstract}

Keywords: Thermodynamics, List of exercises, Physical Learning.

\section{INTRODUÇÃO}

A termodinâmica é uma importante área da física que lida com conceitos e fenômenos relacionados à temperatura e ao calor. Nesse viés, vale ressaltar que a natureza da termodinâmica é bem diferente dos conceitos estudados em dinâmica, apesar dos nomes sugerirem o contrário, segundo Moyses (1998), onde termo é igual a temperatura e dinâmica está relacionado ao movimento dos corpos.

Como parte da termodinâmica, estuda-se o comportamento dos materiais sob variações 
de temperatura, onde experimentalmente, verifica-se que os corpos se dilatam ou se contraem quando submetidos a uma variação positiva ou negativa de temperatura. Esse efeito descrito é conhecido como "dilatação térmica". Pode-se dizer que esse efeito se caracteriza como principal aplicação para esse fenômeno, ao qual o termômetro de mercúrio, que era frequentemente utilizado para medir a temperatura corporal das pessoas em farmácias e hospitais, de acordo com (TIPLER, 2009).

Em paralelo a esse conceito, será abordada a definição de calor que nada mais é do que o fluxo de energia entre dois corpos, devido uma diferença de temperatura. Esse conceito divide-se em dois outros, sendo eles o calor específico e o calor latente. O calor latente é a energia necessária para que determinado material mude de fase, esse conceito se difere do conceito de calor sensível pelo fato de que o calor sensível é o calor necessário para que um objeto mude sua temperatura (MOYSES, 1998). Ligado ao conceito de calor sensível, com isso a capacidade térmica, que é a quantidade de calor necessária para que um quilograma de água mude sua temperatura em um grau (HALLIDAY, 2018).

Devido às linguagens do cotidiano, é comum atribuir o conceito de calor ao que diz respeito à temperatura (TIPLER, 2009). Cabe então ao professor apontar as principais diferenças desses dois conceitos em sala de aula para que os alunos percam esse vício de linguagem.

Nesse cenário, é de grande importância que o educando esteja atento a determinados fatos acontecidos corriqueiramente em seu cotidiano, fatos esses que trazem o conceito errôneo de determinados fenômenos, nesse caso, o calor. Dessa forma se torna mais provável a existência de cidadãos capazes de compreender a sociedade em que vivem, sendo possível atuarem na sociedade compreendendo e identificando que a física está presente nos mais diversos fatores do cotidiano. Para tal, é necessário apontar vários e diferentes exemplos no cotidiano e exercitar os conceitos da termodinâmica. A aprendizagem da física não deve está permeada apenas em fixar conceitos para memorização, a mesma deve consistir em estratégias que possam possibilitar ao aluno a atribuir sentido no que foi repassado em sala com oque é vivenciado no dia a dia.

Diante a situação descrita este trabalho traz por meio de listas de exercício uma forma de explorar as aplicações dos assuntos relacionados à termodinâmica, na qual é proposta listas de exercícios contextualizadas onde os problemas de dilatação térmica e calor estarão envoltos de uma história fictícia sobre perícia criminal e física médica, a fim de melhorar a interpretação dos alunos e aplicar as ideias principais dessa área da física em assuntos reais do dia-a- dia. Solé (2014, p. 40) diz que se faz possível atribuir sentido, significado no que se lê, 


\section{PROPOSTA DE USO DE LISTAS DE EXERCÍCIOS}

"a partir do conhecimento prévio, a partir daquilo que já se sabe".

Através dessas listas de exercícios interativos busca-se promover uma aprendizagem de conceitos de física. Onde o aluno estaria praticando não só os conceitos físicos, mas também a interpretação de texto, algo essencial, visto que é comum, alunos que apresentam dificuldades de interpretação. As dificuldades que assolam os alunos na interpretação de texto não se mostram apenas nas aulas de língua portuguesa é algo que é recorrente em qualquer outra disciplina. Dessa forma, trabalhar a interpretação de textos deve ser algo em que todos os educadores podem e devem trabalhar, pois, a habilidade de interpretar é primordial em qualquer disciplina. Enfim, a leitura de textos faz com que os estudantes consigam ir mais além, pois a leitura promove a integração entre os conceitos, equações, resoluções de problemas e suas aplicações no cotidiano.

\section{FUNDAMENTAÇÃO TEÓRICA}

O presente artigo está dividido em tópicos, dos quais serão trabalhados acerca da importância dos estudos físicos e conceitos dos mesmos abordando primeiramente algumas classificações de temperatura, termômetro e calor em seguida abordaram a temática do ensino de física em seguida a importância da utilização da lista de exercícios. Com isso segmentar as temáticas abordadas.

\section{TEMPERATURA, TERMÔMETRO E CALOR.}

A temperatura é um conceito que está presente no cotidiano e em quase tudo que se possa imaginar, desde as chamas na boca dos fogões, até aos próprios corpos, contudo, sua definição se confunde às vezes com a definição de calor. Com base na teoria cinética dos gases, pode-se afirmar que a temperatura é o grau de agitação das moléculas de determinados materiais. De acordo com Hewiit (2015), a quantidade que informa quão quente ou frio é um objeto em relação a algum padrão é chamada de temperatura. Ainda relacionado a isso, Tipler (2009), descreve que a observação desse grau de agitação pode ser obtida com base nos termômetros.

Sabe-se que o termômetro foi o primeiro "medidor térmico", sendo inventado e desenvolvido por Galileu em 1602. Ainda relacionado ao termo, é importante destacar que segundo Hewiit (2015), a palavra térmico é o termo grego para “calor”. Esse curioso objeto macroscópico consegue medir o grau de agitação de partículas microscópicas com base numa propriedade da matéria chamada de dilatação térmica dos corpos. Devido a essa dependência que o termômetro tem com o material que vai dilatar, podem-se apresentar 
diferentes escalas de medida para um mesmo evento térmico. Por exemplo, a temperatura em que a água ferve, na escala Celsius é $100^{\circ}$, já na escala Fahrenheit é $212^{\circ}$, dentre outras. Para evitar essa dependência, construiu-se uma escala absoluta, a chamada escala Kelvin. Foi definido que essa escala seria então a unidade de medida da temperatura (TIPLER, 2009).

Partindo dessa ideia de dilatação, serão trabalhadas através de equações que determinam a variação linear, superficial e volumétrica (respectivamente) dos materiais devido uma diferença de temperatura, que é dada pelas equações:

$$
\begin{aligned}
& \Delta L=L_{0} \alpha \Delta T \\
& \Delta A=A_{0} 2 \alpha \Delta T \\
& \Delta V=V_{0} 3 \alpha \Delta T
\end{aligned}
$$

Em que $\alpha$ é o coeficiente de dilatação linear do material, $\Delta T$ a variação de temperatura. $L_{0}, A_{0}, V_{0}$ são o comprimento, a área e o volume inicial, respectivamente.

No presente trabalho o calor é abordado na verdade o trânsito de energia entre dois objetos devido uma diferença de temperatura. No final do século XVIII havia duas hipóteses sobre o que de fato era calor. Alguns como Lavoisier acreditava que o calor era na verdade um fluido que permeia toda a matéria e que fluía de um corpo de temperatura maior para um de temperatura menor, já outros como Newton, acreditavam que o calor era um minúsculo movimento de vibração das partículas dos corpos (MOYSES, 1998).

O calor, no entanto, divide-se em dois conceitos dependentes do processo. Quando as substâncias mudam de fase, o calor necessário para que o estado da matéria mude é chamado de calor latente. Quando um corpo troca energia com outro, a variação de sua temperatura está relacionada ao fluxo de energia chamada de calor sensível (HALLIDAY, 2012).

A equação matemática referente ao calor sensível é:

$$
Q=m c \Delta T
$$

Em que $c$ é o calor específico do material, $m$ a massa da amostra e $\Delta T$ é a variação de temperatura. Para calcular o calor latente é utilizada a seguinte equação: 


$$
Q=\boldsymbol{m} \cdot \boldsymbol{v}
$$

Onde $Q$ é a quantidade de calor, $m$ a massa e $l$ é o calor latente.

\section{O ENSINO DA FÍSICA}

O ensino da física é um componente curricular do ensino médio ao qual está presente na grade curricular como é o caso da biologia, química e matemática, em síntese a isso se observa que as mesmas encontram dificuldades, na temática pertinente de ensino dos alunos em áreas que envolvem estes componentes curriculares, conforme aponta Borges (2016, p. 20):

Os estudos e as pesquisas que analisam a situação em que se encontra o ensino de Física nas escolas de Ensino Médio evidenciam uma preocupante realidade com relação ao desempenho escolar dos alunos nessa disciplina e sugerem a necessidade de mudanças.

Borges (2016, p. 20) continua:

Esse é um problema comum no Brasil e que muitas vezes deixa a impressão no aluno que a Física se resume à aplicação de fórmulas para se resolver exercícios, deixando de lado a discussão e os entendimentos dos conceitos envolvidos na disciplina.

Conforme apontado nos estudos citados, onde os mesmos abordam que as dificuldades enfrentadas pelos alunos se relacionam com o que é visto em sala de aula na disciplina e a vida cotidiana dos mesmos, ou seja, passam a evidenciar acerca da importância do professor em ministrar aulas que ponha em centralização metodologias que proporcionem ao aluno um maior aprendizado.

Godoi (2018) aponta em seu artigo que:

Considera ainda, que muitas das dificuldades podem surgir dado que os conceitos da Física são contra-intuitivos, ou seja, não seguem nenhuma lógica já conhecida pelos discente até então, dificultando a compreensão e, consequentemente, a aplicação dos conteúdos estudados no cotidiano deles, e que não são pensados pelo professor.

Tais pensamentos compõem a ideia de que o desinteresse entre os alunos pelo conteúdo ministrado pelo professor em Física é a não associação do que é ensinado em sala de aula, com o que é vivido por eles no dia a dia. Ou seja, os mesmos não enxergam a física aprendida em sala concernente às experiências vividas fora do contexto escolar. Com isso as abordagens de Domingues et all (2000, p. 64) levantam alguns aspectos que atingem a nossa 
educação:

Falta tempo para sua implantação e consolidação no espaço de um governo, acarretando descontinuidade administrativa e pedagógica. O mais grave é que tais políticas levam ao descrédito no âmbito escolar, uma vez que os professores não acreditam nelas, e, portanto, não se engajam efetivamente.

Durante todas estas reformas que estão sendo evidenciadas ao prólogo deste material até onde se destaca a ideia da criação da Base Nacional Comum Curricular (BNCC) importante e indispensável organização no que diz respeito a educação brasileira - e desde a Constituição de 1988 no seu artigo 210, onde a mesma aborda que "serão fixados conteúdos mínimos para o Ensino Fundamental, de maneira a assegurar formação básica comum e respeito aos valores culturais e artísticos, nacionais e regionais" (BRASIL, 2016, p. 332).

A Base Nacional Comum Curricular (BNCC) em sua conceituação acerca da Física expõe a importância da disciplina, e como ela deve ser abordada tendo em vista o desenvolvimento histórico e as possibilidades que surgem ao estudar a disciplina. Assim, sua contribuição perpassa pela abordagem sobre leis e princípios e pode contribuir para que a escola possa cumprir com a responsabilidade de promover a compreensão de fenômenos físicos. Compondo assim as práticas educacionais que visam trazer ao aluno princípios, como conservação, conversão e degradação da energia ou conservação de quantidades de movimento, explicando os fenômenos como a cor do céu ou de chamas, a luz de raios ou de lâmpadas, a radiação solar ou de motores aquecidos e a explosão de artefatos ou de estrelas, por exemplo, (BRASIL, 2016). O referido documento estabelece que:

\footnotetext{
Estudantes que começam compreendendo que quedas se devem à gravidade terrestre, que sinais de rádio vêm em ondas eletromagnéticas e que as radiações alfa, beta e gama são de origem nuclear podem, ainda, se encantar com a história de estrelas como o Sol. Os conceitos e modelos da Física nos ajudam a descrever e a interpretar o mundo a nossa volta, sejam sistemas naturais ou equipamentos tecnológicos. Como corpo organizado de conhecimentos, a Física representa uma maneira de dialogar com o mundo, uma forma de "olhar o real", que apresenta características peculiares, como a proposição de representações, modelos, leis e teorias com alto grau de abstração, sofisticação, consistência e coerência internas. [...] (BRASIL, 2016, p. 143).
}

\section{O USO DA LISTA DE EXERCÍCIOS NO ENSINO DE TERMOLOGIA}

O uso de lista de atividades contextualizadas com foco no processo ensinoaprendizagem apresenta-se como mais uma alternativa para incrementar o aprendizado de termologia, tendo em vista a superação das dificuldades que o mesmo encontra na disciplina 


\title{
PROPOSTA DE USO DE LISTAS DE EXERCÍCIOS
}

uma das probabilidades que enfatizam o conhecimento do aluno.

O uso destas listas de exercícios busca também subsidiar o trabalho de professores de Física, visando incentivar novas formas de promover o conhecimento através de práticas com as quais os alunos sintam-se como propagadores deste conhecimento, a aplicação desta lista de exercícios se diferencia das demais, pois a mesma contextualiza os conteúdos abordados de uma forma mais gradual e que foge da contextualização de uma lista de exercicios comum, pois segundo Boeira et all (2009):

\begin{abstract}
Os alunos percebem quando o professor se importa com eles e com seu aprendizado. Se nos dispomos a fazer algo de novo em sala de aula, com atividades diferenciadas visando à melhor compreensão do conteúdo, e tornando as aulas momentos prazerosos e gratificantes, imediatamente recebemos a resposta a esta iniciativa. Se o professor deixa claro seus objetivos os alunos mostram emprenho na realização das atividades, formando uma parceria com o professor. (BOEIRA et all, p. 7, 2009).
\end{abstract}

Estas reflexões levam a entender que a prática docente tem de acompanhar o desenvolvimento dos alunos de tal forma a contextualizar e familiarizar estes a conteúdos e práticas mais interessantes, práticas estas que podem ser trabalhadas em uma atividade da lista de exercícios. Na elaboração destas atividades para solucionar as questões da lista de exercícios, ocorre a ampliação do pensamento e a linguagem modifica-se em função do que se pretende explicar.

\section{INTERPRETAÇÃO NO ENSINO DE FÍSICA}

No ensino das disciplinas exatas, em particular na Física, não se costuma evidenciar a leitura. Sendo que ler é importantíssimo para o aprimoramento e o sucesso de qualquer estudante em qualquer área. Ler é fundamental tanto para as disciplinas de linguagens como de ciências exatas. Valendo destacar que além de ler, saber interpretar um problema facilita sua resolução, e na sala de aula o mais comum são alunos que não conseguem interpretar os problemas físicos, para assim poder resolver algum exercício. Claro que outros fatores colaboram para esse fato como afirma Ferrari (2020):

Da análise das dificuldades apresentadas pelos alunos diante de determinados exercícios de física tende a ir muito além de uma simples deficiência em interpretação de texto, o que seria minimizar um caso cuja abordagem não se tem mostrado simples. Em se tratando especificamente de física, uma das principais fontes de baixa compreensão de uma tarefa proposta é o fato de esta ser uma ciência cujas conclusões acerca dos fenômenos naturais são interpretadas de modo não proposital no cotidiano e, por isso, de forma potencialmente equivocada. (FERRARI, p. 1, 2020) 
O ensino de Física baseia-se muito no livro didático e acaba que os alunos e muitos professores usam apenas o livro como ferramenta para a sala de aula. No entanto, os textos que esses livros trazem, são resumos que buscam definir apenas os conceitos e equações sem contextualizá-los, não trazem uma conexão com a vida do aluno. Fazer o uso de textos alternativos como complemento dos livros didáticos pode ser algo a trazer benefícios para a aprendizagem do aluno.

Segundo Silva e Almeida (2000), textos alternativos podem ser escritos em linguagem informal, menos técnica, a fim de trazerem conteúdos atuais, e trazendo vínculos com a vida dos alunos. Neste contexto, o professor, como principal responsável pela organização da aula, desempenha um papel fundamental apresentando questões, proporcionando situações que produzam uma ligação da física da teoria com a realidade, integrando textos interativos com o conteúdo, para que assim o aluno consiga desenvolver, ler e trabalhar essa interpretação.

\section{METODOLOGIA}

Inicialmente é importante ressaltar que a metodologia do presente trabalho se trata de uma pesquisa bibliográfica, devido a necessidade de buscar apoio em literaturas já existentes. Trata-se, também de uma pesquisa descritiva uma vez que apresenta atividades para execução, e além disso, se trata também uma pesquisa exploratória, que através de uma lista de exercícios que tem como objetivo apresentar a importância do ensino da física para qualquer indivíduo inserido em uma sociedade cada vez mais exigente para com os conhecimentos de cada um. Com isso, o trabalho traz consigo estratégias de ensino da física, isso com a aplicação de exercícios.

A aplicação das listas de exercícios será realizada logo após ministrar as aulas referentes a cada conteúdo, tal como segue o exemplo abaixo de como pode ser aplicado:

\begin{tabular}{|c|l|l|}
\hline Conteúdo & Período & Lista \\
\hline Temperatura & Duas aulas & Crise no avião \\
e \\
Termômetros & & \\
\hline Calorimetria & Duas aulas & A noite de crime \\
\hline
\end{tabular}

*A SEGUIR AS LISTAS PROPOSTAS 


\section{PROPOSTA DE USO DE LISTAS DE EXERCÍCIOS}

\section{1 - CRISE NO AVIÃO}

Era uma manhã de quinta-feira, o céu estava bem claro e algumas nuvens em forma de elefante pairavam pelo céu. Eu queria estar lá fora naquele momento, mas não podia porque meu avião já estava prestes a decolar. Já fazia quase duas horas que eu esperava naquele gigantesco e lotado aeroporto.

Escuto uma chamada no alto-falante e tiro minha atenção das nuvens. Um homem de terno e bigode passa pela minha frente conversando alto pelo celular, mas logo me contorço e direciono minha atenção para o alto falante. Uma voz robótica feminina, diz:

- Atenção senhores passageiros, o avião para São Paulo já está de saída. Dirijam-se imediatamente a plataforma.

Aquele era o meu avião. Fiquei aliviado por ele não se atrasar, caso contrário, eu perderia o horário de ir para o hotel de meu colega, antes da conferência científica de física e engenharia. Levantei rapidamente e me apressei em chegar logo ao meu objetivo.

Enquanto eu embarcava no avião, uma leve brisa percorria o lugar. Espirro. Uma moça que estava logo a minha frente olhou para trás meio assustada (a pandemia tinha acabado, mas as pessoas ainda se preocupavam com aquela doença). Imediatamente coloquei minha máscara de algodão e prossegui adentrando no avião.

Enquanto andava pelo corredor em busca de meu assento, noto que havia um homem de cara pálida e respiração ofegante. Poderia ser que aquele era o jeito natural dele, porém, meus instintos me diziam que aquilo não era normal, porém, apenas sentei em meu lugar e aguardei a decolagem. Aquele foi meu erro.

Passou-se meia hora de voo e escuto uma senhora gritando. A aeromoça corre rapidamente até o local bem próximo a mim. Eu me contorço para observar o que estivera acontecendo e me deparo com aquele mesmo homem pálido de antes. Ele havia desmaiado.

As pessoas no lugar começam a entrar em pânico, principalmente a esposa do homem pálido. A aeromoça se levanta e olha pra suas colegas de equipe. Todas estavam em choque e não sabiam o que fazer. Uma das mulheres então fala mais alto:

- Atenção! Existe algum médico aqui que possa nos ajudar?

Eu me ergo da cadeira e falo:

- Senhoras, eu estudei um pouco de medicina no meu curso de física médica, só que meu equipamento não está comigo, a única coisa que tenho é esse bisturi — eu o retiro do bolso.

— Nosso avião só tem máscaras de oxigênio — disse a mulher.

$\mathrm{Eu}$ penso por alguns segundos. Então me vem logo uma ideia de como medir a temperatura daquele homem usando meu bisturi. Então, caminho até o homem caído. 
— Existe algum engenheiro aqui que tenha um equipamento de alta precisão? — perguntei enquanto ouvia o coração do homem caído.

— Eu tenho! - Disse uma mulher de cabelos negros. De sua bolsa, ela tira uma pequena régua - essa régua tem uma precisão da ordem de micrômetros. Quando você mede usando esses pontos escuros, aparece um número digital indicando a medida.

— Ótimo! — Eu a pego em minhas mãos.

Sorte que naquele momento eu lembrava o conceito de temperatura.

\section{$1^{\text {a }}$ Temperatura, nada mais é do que:}

Eu coloco o bisturi em minha pele e deixo lá por um minuto até que ele entre em equilíbrio térmico com meu corpo. Pego então a régua e meço a variação de comprimento do bisturi. Logo me lembro que isso ocorre porque:

\section{$2^{\mathrm{a}}$ A dilatação dos corpos nada mais é do que:}

\section{$3^{\text {a }}$ Além disso, os três tipos de dilatação são:}

Sabendo o tipo de dilatação que ocorre, eu meço que a variação de comprimento no bisturi $\left(\Delta L_{n}\right)$ é de 0,5 milímetros. Além disso, eu sei que a temperatura no avião e a do bisturi, inicialmente é de $27^{\circ} \mathrm{C}$, portanto, a variação de temperatura usando minha pele com temperatura normal $\left(\Delta T_{n}\right)$, é de $10^{\circ} \mathrm{C}$, já que a temperatura normal do ser humano é de $37^{\circ} \mathrm{C}$. $4^{\circ}$ Após isso, faço o mesmo que fiz em mim, no homem caído e noto que sua variação de comprimento $(\Delta L)$ é de 0,55 milímetros, portanto, usando a equação:

$$
\Delta T=\frac{(\Delta L)}{\left(\Delta L_{n}\right)}\left(\Delta T_{n}\right)
$$

- Determino que a variação de temperatura é de:
a) ( ) $12^{\circ} \mathrm{C}$
b) ( ) $11^{\circ} \mathrm{C}$
c) ( ) $10^{\circ} \mathrm{C}$
d) ( ) $13^{\circ}$
e) ( ) $15^{\circ}$

- E que a temperatura final do paciente é, portanto:
a) ( ) $37^{\circ} \mathrm{C}$
b) ( ) $38^{\circ} \mathrm{C}$
c) ( ) $39^{\circ} \mathrm{C}$
d) ( ) $41^{\circ} \mathrm{C}$
e) ( ) $40^{\circ} \mathrm{C}$

Com esse resultado, percebo que o paciente estava apenas com um valor elevado de febre, então digo a aeromoça para parar no primeiro aeroporto, a fim de fazer os primeiros socorros no homem.

\section{2 - A NOITE DE CRIME}




\section{PROPOSTA DE USO DE LISTAS DE EXERCÍCIOS}

\section{Para resolver a lista, vocês devem ler o texto e responder as perguntas propostas.}

Ao final, devem indicar com base em seus resultados, quem é o culpado.

Era uma sexta-feira chuvosa, quando eu e meus companheiros detetives, Max e Amanda estávamos analisando uma noite de crime. Sei bem que poderia estar num bar com os amigos tomando uma, mas ainda era hora de serviço, por isso, eu tinha que focar no que estava acontecendo ali.

Amanda caminhava pela sala empoeirada em busca de pistas, enquanto eu e Max discutimos sobre o que poderia ter acontecido naquele lugar e sobre os suspeitos que encontramos. Foi visto às $18 \mathrm{~h}$ que um ferreiro corria apressadamente perto da casa em que nos encontramos, além disso, às 19h tinha uma moça da igreja que caminhava vagarosamente até um orelhão. Parece que ela foi à pessoa que contatou a polícia.

- Por enquanto temos dois suspeitos e nenhuma pista - Max falou olhando para mim.

— Nós temos uma pista! - Disse Amanda enquanto caminhava até nós segurando uma pinça com um objeto - parece que isso é uma bala!

— Olha só, isso é uma ótima pista - Eu disse, segurando na pinça e colocando a bala num saco plástico transparente.

Caminhei até próximo da porta.

- Levarei esse objeto para analisar. Acho que precisamos descobrir de que material essa bala foi feita.

Para minha surpresa, havia uma moça de cabelos cacheados nos observando. Ao que parecia, ela era uma professora. Seu olhar assustado se dirigiu a mim e sua respiração ofegante me deixou desconfiado.

— O que você faz aqui? Isso é uma cena de crime e tá proibida à entrada! — A repreendi.

- Desculpe, senhor, a pessoa morta se chamava Rafael e ele era meu vizinho - disse a mulher, mexendo em seu chapéu. Seu broche de prata me chamou atenção, era realmente muito bonito.

A moça então segue caminho até uma casa. Não pude deixar de notar que ela andava com uma bolsa, também revestida de prata. Ao entrar no carro, consegui observar que o nosso primeiro suspeito, o ferreiro, estava sentado numa cadeira de madeira. Ele parecia preocupado com alguma coisa. Não liguei e apenas segui até o laboratório.

$* * *$

No laboratório, eu caminho até uma grande mesa de madeira, nela, havia uma grande caixa de vidro. Eu uso então um fogão para aquecer a água ali dentro e então fíco me 
PRINCIPAL, et al.

perguntando:

\section{O calor envolvido nesse processo de aquecimento é:}
a) ( ) Latente
b) ( ) Sensível
c) ( ) Transcendente
d) ( ) Trabalhado

Após variar a temperatura de $27^{\circ}$ para $100^{\circ}$, percebo que a água começa a querer ferver e, por curiosidade, tento medir a temperatura do vapor de água que está saindo usando meu termômetro e vejo que a temperatura é:
a) () $\mathbf{1 0 0}^{\circ}$
b) ( )Maior que $100^{\circ}$
c) ( )Menor que $100^{\circ}$
d) ( ) $50^{\circ}$
e) ( ) $90^{\circ}$

Eu então tiro a bala de dentro do saco e resolvo colocar dentro da caixa de vidro, mas ainda não o faço. Eu desliguei o fogo antes de fazer isso, por isso, a temperatura da água nesse momento ainda era de $100^{\circ}$. Eu então vejo em meu fogão a quantidade de calor que foi utilizado para aquecer a água de $27^{\circ}$ para $100^{\circ}$ e vejo que o valor era de $Q=305,14 \cdot 10^{3} \mathrm{~J}$. A capacidade térmica da água é então:

Obs: Use a equação:

$$
C=\frac{Q}{T_{f}-T_{0}}
$$

a) () $17,46.10^{3} \mathbf{J} / \mathbf{K} \quad$ b) ( ) $4,18 \cdot 10^{3} \mathbf{J} / \mathbf{K} \quad$ c) ( ) $305,14 \cdot 10^{3} \mathbf{J} / \mathbf{K}$

\section{d ( ) $306,14 \cdot 10^{3} \mathbf{J} / \mathbf{K}$ e) ( ) $315,14 \cdot 10^{3} \mathbf{J} / \mathbf{K}$}

Após medir a capacidade térmica da água, coloco a bala dentro da caixa de vidro e deixo que a energia flua da água para a bala, já que a bala tem temperatura inicial de $27^{\circ}$. Após um tempo, percebi que a temperatura da água e da bala é de $99,6^{\circ}$. Sabendo que a capacidade térmica da água vale $4,18 \cdot 10^{3} \mathrm{~J} / \mathrm{g}$, uso a equação do calor para determinar qual a capacidade térmica da bala. Percebo então que o resultado dá:

Obs: Use a equação

$$
Q_{1}=-Q_{2}
$$

em que $Q_{1}=C_{1}\left(T_{f}-T_{01}\right)$ e $Q_{2}=C_{2}\left(T_{f}-T_{02}\right)$
a) ( ) $96,19 \mathbf{J} / \mathbf{K}$
b) ( ) $23,03 \mathrm{~J} / \mathrm{K}$
c) ( ) $1681 \mathrm{~J} / \mathrm{K}$
d) ( ) $1781 \mathrm{~J} / \mathrm{K}$
e) ( ) $181 \mathrm{~J} / \mathrm{K}$

Após encontrar o resultado (a bala era feita de prata), eu recebi uma ligação. Eu então digo aos meus colegas o resultado que encontrei e eles logo batem o martelo sobre quem foi o criminoso naquela noite. Eu fico surpreso!

Some os pontos que você obteve com suas respostas. Cada letra a) vale 10 pontos, 


\section{PROPOSTA DE USO DE LISTAS DE EXERCÍCIOS}

cada letra $b$ ) vale 20 pontos e cada letra c) vale 30 pontos.

Com base em seus pontos, o verdadeiro culpado do crime foi:

( ) $O$ ferreiro- 120 pontos

( ) A moça da igreja- 50 pontos

( ) A professora - 70 pontos

\section{CONSIDERAÇÕES FINAIS}

Buscou-se mostrar com esse trabalho que é possível prender a atenção dos alunos do ensino médio mesmo durante a resolução de listas de exercícios de uma disciplina muitas vezes negligenciada pelos alunos e professores. Com a pesquisa foi possível perceber que além dos exercícios se tornar uma excelente fonte de aprendizado, também faz com que o aluno tenha interesse em participar das aulas. Acredita-se que se as demais disciplinas aderirem a esse tipo de lista, norteará os alunos quanto a sua escolha profissional. $\mathrm{O}$ artigo também pode ser considerado como uma fonte de divulgação científica de trabalhos que um físico pode exercer na sociedade, uma vez que o estudo nessa área é de extrema importância para entender diversos acontecimentos corriqueiros.

Com isso o presente artigo traz em suma, uma abordagem teórica acerca do uso da lista de exercícios como um importante precursor do conhecimento. A lista desenvolvida segue as orientações das aulas e ao fim da aula, o professor repassa aos alunos uma lista de exercícios contextualizada com a temática abordada nas aulas. Para que isso seja possível é preciso contextualizar o ensino de física através de teorias, e as práticas de ensino, conforme a Base Nacional Curricular (BNCC) além de outras bases teóricas.

O estudo realizado foi de grande importância para o desenvolvimento acadêmico dos autores, uma vez que, com a leitura e a execução, ou seja, a prática, o aprendizado se torna muito mais potencializador. A estratégia de ensino tratada aqui é de grande importância para o alunado não somente para saber distinguir determinadas situações, mas ajuda também no seu desenvolvimento enquanto ser humano vivendo em sociedade e que necessita de conhecimento para que ocorra uma melhor interação com o mundo a sua volta.

\section{REFERÊNCIAS}

BRASIL. Ministério da Educação. Base Nacional Comum Curricular $-2^{\mathrm{a}}$ Versão do documento preliminar. MEC. Brasília, DF, 2016a. 
BORGES, L. B. Ensino e aprendizagem de Física: contribuições da teoria de Davydov. 2016. 154 f. Tese (Doutorado em Educação),Pontifícia Universidade Católica, Goiânia, 2016.

D. Halliday, R. Resnick e J. Walker, Fundamentos de Física (LTC editora, Rio de Janeiro, 2012), vol. $2,9^{\mathrm{a}} \mathrm{ed}$.

FERRARI, G. Otimização da interpretação de enunciados de física através de metodologias ativas. Disponível em http://www1.fisica.org.br/fne/phocadownload/Vol18-Num1/FnE-18-1190506.pdf. Acesso em: 20/ 10/ 2021

HEWITT, P. Física conceitual (Bookman editora ltda, 2015), volume único, $12^{\circ}$ ed.

H.M. Nussenzveig, Curso de Física Básica (Edgard Blücher, São Paulo, 1997), v. 2, $1^{a}$ ed.

MICHELENA; BOEIRA; MACHADO. Texto de Apoio ao Professorde Física - Física térmica: uma abordagem histórica e experimental. Programa de Pós- graduação em Ensino de Física. V.20, n 5, 2008.

SBF, SOCIEDADE BRASILEIRA DE FÍSICA (2015). A Física no ensino médio e fundamental: proposta para a SBF. Considerações sobre a Base Nacional Curricular Comum e a física na BNCC (Ensino Médio e Fundamental). Disponível em: http://www.sbfisica.org.br/v1/arquivos_diversos/ Acesso em: 22 de julho. 2021.

SILVA, H. C. Uma revisão de trabalhos sobre o funcionamento de textos alternativos ao livro didático no ensino de Física. Monografia - CE-FE-Unicamp; II Encontro Internacional de Pesquisa en Educação em Ciências, 2000.

SOLÉ, I. Estratégias de leitura. 6 ed. Porto Alegre: Penso, 2014.

TIPLER, Paul A.; MOSCA, G. Física para cientistas e engenheiros (Rio de Janeiro: LTC, 2009), vol. 1. $6^{\mathrm{a}} \mathrm{ed}$. 